\title{
Phytochemical content and antioxidant activity of grapefruit (Star Ruby): A comparison between fresh freeze-dried fruits and different powder formulations
}

\author{
Claudia Agudelo ${ }^{\mathrm{a}, \mathrm{b}}$, Lillian Barros ${ }^{\mathrm{a}, \mathrm{c}}$, Celestino Santos-Buelga ${ }^{\mathrm{d}}$,

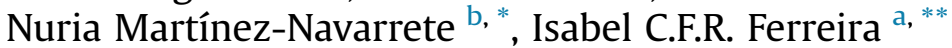 \\ ${ }^{a}$ Mountain Research Centre (CIMO), ESA, Polytechnic Institute of Bragança, Campus de Santa Apolónia, 1172, 5300-253 Bragança, Portugal \\ ${ }^{\mathrm{b}}$ Universidad Politécnica de Valencia, Departamento de Tecnología de Alimentos, Grupo de Investigación e Innovación Alimentaria, Camino de Vera s/n, \\ 46022 Valencia, Spain \\ ${ }^{\mathrm{c}}$ Laboratory of Separation and Reaction Engineering - Laboratory of Catalysis and Materials (LSRE-LCM), Polytechnic Institute of Bragança, Campus de \\ Santa Apolónia, 1134, 5301-857 Bragança, Portugal \\ ${ }^{\mathrm{d}}$ GIP-USAL, Facultad de Farmacia, Universidad de Salamanca, Campus Miguel de Unamuno, 37007 Salamanca, Spain
}

\section{A R T I C L E I N F O}

\section{Article history:}

Received 2 August 2016

Received in revised form

22 December 2016

Accepted 4 February 2017

Available online 12 February 2017

\section{Keywords:}

Spray-drying/Freeze-drying

Antioxidant activity

Bioactive compounds

Arabic gum

Bamboo fiber

\section{Chemical compounds:}

Ascorbic acid (PubChem CID: 54670067)

Alpha-Tocopherol (PubChem CID: 14985)

Naringin (PubChem CID: 25075)

Narirutin (PubChem CID: 442431)

2,2-Diphenyl-1-(2,4,6-trinitrophenyl)

hydrazyl (PubChem CID: 2735032)

Potassium ferricyanide (PubChem CID:

26250)

Beta-carotene (PubChem CID: 5280489)

Thiobarbituric acid (PubChem CID:

2723628)

Trolox (PubChem CID: 40634)

\begin{abstract}
A B S T R A C T
Different grapefruit powders obtained by freeze drying and spray drying with prior addition of shell materials (arabic gum and bamboo fiber) were studied in order to evaluate the effect of these preservation processes on the retention of antioxidants, in comparison with the freeze-dried fruit with no carriers added. Freeze-dried samples showed above $90 \%$ retention of these phytochemicals, while spraydried samples presented good retention of vitamins but a sharp decrease in of phenolic compounds. Pearson's correlation analysis showed that the most significant contribution to DPPH scavenging activity and inhibition of $\beta$-carotene bleaching was provided by phenolic compounds, mostly flavonoids, while the contribution to the reducing power was due to ascorbic acid and $\alpha$-tocopherol. Therefore, the loss of these compounds in the spray-dried samples resulted in products with lower antioxidant activity. Naringin and narirutin were the major phenolic compounds in all grapefruit samples, although other flavanones present in lower concentration, like hesperidin, neohesperidin didymin, poncirin or melitidin, also showed high correlations with the antioxidant value of the samples.
\end{abstract}

๑) 2017 Elsevier Ltd. All rights reserved.

\footnotetext{
* Corresponding author.

** Corresponding author.

E-mail addresses: nmartin@tal.upv.es (N. Martínez-Navarrete), iferreira@ipb.pt (I.C.F.R. Ferreira).
}

\section{Introduction}

Grapefruit is a very common variety of citrus fruit and an important source of bioactive compounds such as vitamins C, E, A, phenolic compounds (flavonoids, phenolic acids and coumarins), and terpenic substances, such as carotenoids and limonoids (Kelebek, 2010; Zou, Xi, Hu, Nie, \& Zhou, 2015). In recent years, the phenolic compounds present in grapefruit have been investigated, 
and some publications have suggested that they could play an important role in the antioxidant capacity of grapefruit juice (Gorinstein et al., 2005; Xu et al., 2008), which has been related with the prevention of different chronic diseases including heart disease, obesity, diabetes, cardiovascular diseases and cancer (Mertens-Talcott, Zadezensky, De Castro, Derendorf \& Butterweck, 2006; Vanamala, Reddivari, Yoo, Pike, \& Patil, 2006; Díaz-Juárez et al., 2009). Some epidemiological studies also pointed to the consumption of grapefruit brings benefits in weight loss and improve lipid metabolism (Dow, Going, Chow, Patil, \& Thomson, 2012; Gorinstein et al., 2005). However, despite its high functional value, the consumption of fresh grapefruit is low, probably due to its strong bitter taste and also because it is produced on a seasonal basis, so that in many countries it may not be available in fresh conditions throughout the year. Dried and powdered products can overcome this problem, as they more stable than fresh fruit and easier to store and distribute, making them available all around the year. Freeze-drying and spray-drying are two techniques used for the production of fruit powder (Fernandes, Rodrigues, Law, \& Mujumdar, 2011). Nevertheless, the process used to obtain the powder must ensure the maximal preservation of the bioactive or functional fruit compounds, with the type of shell materials used to protect those compounds playing an important role in the antioxidant capacity of the final product (Tonon, Brabet, Pallet, Brat, \& Hubinger, 2009; Fang \& Bhandari, 2012).

In this study, freeze-drying and spray-drying have been applied to obtain powdered grapefruit and their effects on the antioxidant capacity and the levels of ascorbic acid, $\alpha$-tocopherol and phenolic compounds of the product have been investigated and discussed. The effect of arabic gum and bamboo fibre added as shell materials has been considered.

\section{Materials and methods}

\subsection{Raw material}

The study was carried out with different samples of grapefruit (Citrus paradisi var. Star Ruby) purchased in local supermarkets in Valencia (Spain). Grapefruits were washed and peeled with careful removal of the albedo. Arabic gum (AG, Scharlau, Spain) and bamboo fiber (BF, VITACEL ${ }^{\circledR}$, Rosenberg, Germany) were added to the grapefruit pulp as shell materials for the drying process.

\subsection{Sample's preparation}

Prior to freeze-drying (FD), peeled grapefruits were cut and ground using a bench top food processor (Thermomix TM 21, Vorwerk, Spain), whereas for spray-drying (SD) they were liquidized in a domestic device (DeLonghi, Spain). Six formulations ( 4 for FD and 2 for SD) containing different proportions of the shell materials (AG and $\mathrm{BF}$ ) or water content, selected according to a previous study (Agudelo, Igual, Camacho, \& Martínez-Navarrete, 2016), were prepared (Table 1). For FD formulations, AG and BF were mixed with ground grapefruit and afterwards the samples were placed in aluminium pans (approximately $250 \mathrm{~g}$ in $0.5 \mathrm{~cm}$ thickness by pan) and immediately frozen at $-45{ }^{\circ} \mathrm{C}$ (Liebherr Mediline, LCT2325, Germany) for $48 \mathrm{~h}$ before freeze-drying in a Telstar Lioalfa-6 Lyophyliser at $0.021 \mathrm{~Pa}$ and $-59{ }^{\circ} \mathrm{C}$. The obtained cakes were ground (Kenwood, $\mathrm{CH} 580$, Spain) and sieved to obtain powder with a particle size lower than $0.7 \mathrm{~mm}$. For SD formulations, AG and BF were dissolved in distilled water in the desired proportions and mixed with the liquidized grapefruit in relation 1:1 (AG-BF solutions: liquidized grapefruit). After that, the mixture was fed into a Büchi B-290 (Switzerland) mini spray dryer with the following operating conditions: aspirator rate $90 \%\left(35 \mathrm{~m}^{3} / \mathrm{h}\right)$;
Table 1

Freeze dried ground (GG) or liquidized (LG) grapefruit and different formulations of ground grapefruit used for freeze drying (FD) or liquidized grapefruit used for spray drying (SD).

\begin{tabular}{|c|c|c|c|}
\hline & \multirow[t]{2}{*}{ Formulation } & \multicolumn{2}{|c|}{$\begin{array}{l}\text { Type of shell material and their content (g/ } \\
100 \text { g GG or GL) }\end{array}$} \\
\hline & & Arabic Gum (AG) & Bamboo Fiber (FB) \\
\hline \multicolumn{4}{|c|}{ Freeze dried grapefruit } \\
\hline 1 & GG & - & - \\
\hline 2 & LG & - & - \\
\hline 3 & $\mathrm{FD}_{1}^{\mathrm{a}}$ & 4.2 & 0.58 \\
\hline 4 & $\mathrm{FD}_{2}$ & 4.2 & 0.58 \\
\hline 5 & $\mathrm{FD}_{3}$ & 4.2 & 0 \\
\hline 6 & $\mathrm{FD}_{4}$ & 0 & 0.58 \\
\hline \multicolumn{4}{|c|}{ Spray dried grapefruit } \\
\hline 7 & $\mathrm{SD}_{1}$ & 4 & 2 \\
\hline 8 & $\mathrm{SD}_{2}$ & 4 & 0 \\
\hline
\end{tabular}

atomisation air rotameter $40 \mathrm{~mm}(473 \mathrm{~L} / \mathrm{h})$ with a co-current flow; pump rate $30 \%(9 \mathrm{~mL} / \mathrm{min})$, and drying air inlet temperature $120^{\circ} \mathrm{C}$. After completion of the process and when the air inlet temperature fell below $50{ }^{\circ} \mathrm{C}$, the samples were collected from the product collection vessel for further characterization. To verify the effect of using the carriers, the ground and liquidized grapefruit without shell materials added were also freeze-dried under the same conditions (GG and LG samples, Table 1). It was not possible to spray dry the liquidized sample without carriers.

\subsection{Compound analyses}

\subsubsection{Ascorbic acid}

Ascorbic acid was determined following a procedure previously described by Pereira, Barros, Carvalho, and Ferreira (2013) and the analysis was performed by ultra-fast liquid chromatography coupled to photodiode array detection (UFLC-PDA; Shimadzu Cooperation, Kyoto, Japan), using $245 \mathrm{~nm}$ as preferred wavelength. Results were expressed in $\mathrm{g}$ per $100 \mathrm{~g}$ of grapefruit's own solutes (GS).

\subsubsection{Tocopherols}

Tocopherols were determined following a procedure previously described by Barros, Heleno, Carvalho, and Ferreira (2010), using a HPLC system (Knauer, Smartline system 1000, Berlin, Germany) coupled to a fluorescence detector (FP-2020; Jasco, Easton, USA) programmed for excitation at $290 \mathrm{~nm}$ and emission at $330 \mathrm{~nm}$, using the IS (tocol) method for quantification. The results were expressed in mg per $100 \mathrm{~g}$ GS.

\subsubsection{Phenolic compounds}

Grapefruit samples ( $1 \mathrm{~g}$ ) were extracted with methanol/water $(80: 20, \mathrm{v} / \mathrm{v}, 30 \mathrm{~mL})$ by mechanical maceration $\left(150 \mathrm{rpm}, 25{ }^{\circ} \mathrm{C}\right)$ during $1 \mathrm{~h}$. Afterwards, the sample was filtered using a Whatman no. 4 paper and the residue was re-extracted with an additional portion of the solvent. The extracts were combined and the methanol was evaporated using a rotary evaporator (Büchi R-210; Flawil, Switzerland) and then the aqueous phase was further lyophilized (FreeZone 4.5, Labconco, Kansas City, MO, USA). Each extract $(10 \mathrm{mg})$ was dissolved in water:methanol $(80: 20 \mathrm{v} / \mathrm{v})$, filtered through $0.2 \mu \mathrm{m}$ nylon filters and analysed by HPLC-DADESI-MSn in a Hewlett-Packard 1100 equipment (Agilent Technologies, Waldbronn, Germany) connected to a mass spectrometer (API 3200 Qtrap, Applied Biosystems, Darmstadt, Germany) as previously described by the authors (Pinela et al., 2012). Results 
were expressed $\mathrm{mg} / 100 \mathrm{~g}$ GS.

The dehydrated samples possessed different proportions of added solutes, so that in order to make the results comparable to evaluate the effects of the dehydration processes on the vitamins content and phenolic compounds, the results were referred to the grapefruit's own solutes (GS) according to Eq. (1) and Eq. (2).

$m_{i}=\frac{\left(m_{i p} / m_{p}\right)}{\left(1-x_{w}^{p}\right)\left(x_{G S / T S}\right)}$

$X_{G S / T S}=\frac{m_{g}\left(1-x_{w}^{g}\right)}{\left(m_{A G}+m_{F B} \pm m_{H 20}\left(1-x_{w}^{g}\right)\right)}$

where: $m_{i}$ is the mass of each compound referred to grapefruit solutes $(\mathrm{mg} / \mathrm{g} \mathrm{GS}) ; \mathrm{m}_{\mathrm{ip}}$ is the mass of each compound analysed in the powder $(\mathrm{mg} / \mathrm{g}), \mathrm{x}_{\mathrm{w}}^{\mathrm{p}}$ is the water content of the powder ( $\mathrm{g}_{w a t e r} /$ $\mathrm{g}_{\text {powder }}$ ), $\mathrm{x}_{\mathrm{GS} / \mathrm{TS}}$ is the mass fraction of grapefruit solutes (GS) to total solutes (TS), $m_{g}, m_{A G}$ and $m_{B F}$ are the mass of ground or liquidized grapefruit, arabic gum and bamboo fibre, respectively, in the sample and $x_{w}^{g}$ is the water content of the ground or liquidized grapefruit $(w / w)$.

\subsection{Antioxidant activity}

The methanol/water $(80: 20, \mathrm{v} / \mathrm{v})$ extracts described above (section 2.3.3) were re-dissolved (methanol/water, 80:20, v/v) to a concentration of $10 \mathrm{mg} / \mathrm{mL}$ (stock solution). Six successive dilutions were made starting from the stock solution and further submitted to the different in vitro antioxidant assays as previously described by Fernandes et al. (2016). The antioxidant activity was evaluated using four in vitro assays: DPPH radical-scavenging activity, reducing power, inhibition of $\beta$-carotene bleaching in the presence of linoleic acid radicals and inhibition of lipid peroxidation using TBARS in brain homogenates. The extract concentrations providing $50 \%$ of antioxidant activity or 0.5 of absorbance $\left(E_{50}\right)$ were calculated from the graphs of antioxidant activity percentages (DPPH, $\beta$-carotene bleaching and TBARS assays) or absorbance at $690 \mathrm{~nm}$ (reducing power assay) against extract concentrations. Trolox was used as standard.

\subsection{Statistical analysis}

Analyses of variance (ANOVA) were carried out to evaluate the effect of drying treatments. When the $p$ value was lower than 0.05 , significant differences between samples were considered. Furthermore, a Pearson's correlation analysis between the antioxidant activity and all the analysed compounds was carried out, with a 95\% significance level. All the statistical analyses were performed using Statgraphics Centurion XV.

\section{Results and discussion}

\subsection{Effects on vitamins and phenolic compounds}

The freeze-drying process works with either whole or ground fruits, while spray drying requires an input feedstock with low viscosity and small particle size. For this reason, the grapefruit was liquidized and diluted to obtain a fluid that met the conditions of the spray dryer. Table 2 collects the levels of acid ascorbic and $\alpha$ tocopherol in the different analysed preparations. In general, the values obtained for the content of these vitamins in GG and LG samples were similar to those shown in the literature for ascorbic acid (Moraga, Igual, García-Martínez, Mosquera, \& Martínez-
Table 2

Contents of antioxidant vitamins referred to grapefruit's own solutes (GS). The results are presented as mean \pm SD.

\begin{tabular}{lll}
\hline & $\alpha$-Tocopherol $\mathrm{mg} / 100 \mathrm{~g} \mathrm{GS}$ & Ascorbic acid g/100 g GS \\
\hline Freeze dried grapefruit powder & \\
$\mathrm{GG}$ & $0.60 \pm 0.02^{\mathrm{e}}$ & $0.333 \pm 0.003^{\mathrm{d}}$ \\
$\mathrm{LG}$ & $0.66 \pm 0.03^{\mathrm{cd}}$ & $0.381 \pm 0.003^{\mathrm{a}}$ \\
$\mathrm{FD}$ & $0.96 \pm 0.03^{\mathrm{a}}$ & $0.3331 \pm 0.0002^{\mathrm{d}}$ \\
$\mathrm{FD}_{2}$ & $0.95 \pm 0.03^{\mathrm{ab}}$ & $0.32592 \pm 0.00003^{\mathrm{e}}$ \\
$\mathrm{FD}_{3}$ & $0.93 \pm 0.02^{\mathrm{ab}}$ & $0.33263 \pm 0.00003^{\mathrm{d}}$ \\
$\mathrm{FD}_{4}$ & $0.84 \pm 0.04^{\mathrm{bc}}$ & $0.3240 \pm 0.0007^{\mathrm{e}}$ \\
$\mathrm{Spray}$ & \\
$\mathrm{SD}_{1}$ & $0.677 \pm 0.009^{\mathrm{cd}}$ & $0.3584 \pm 0.0003^{\mathrm{b}}$ \\
$\mathrm{SD}_{2}$ & $0.73 \pm 0.04^{\mathrm{cd}}$ & $0.351 \pm 0.002^{\mathrm{c}}$ \\
\hline
\end{tabular}

Navarrete, 2012) and $\alpha$-tocopherol (Chun, Lee, Ye, Exler, \& Eitenmiller, 2006; [USDA] United States Department of Agriculture, Agricultural Research Service, 2011) in pink grapefruit varieties. Significant differences $(p<0.05)$ were found in the contents of both vitamins between the two samples without shell materials added (GG and LG), with a better vitamin retention in the liquefied fruits further used for preparation of the spray-dried (SD) samples.

According to Park, Lee, and Eun (2016) freeze-drying usually conduct to lower losses in comparison with other techniques like hot air drying, because the low temperature and the absence of oxygen in the drying chamber, this latter being the main cause of losses due to ascorbic acid browning reactions. Similar results were reported by Vanamala et al. (2005) and Moraga et al. (2012), which found that freeze-drying did not reduce significantly vitamin $C$ content in different varieties of grapefruits. As it is shown in Table 2 , the retention of this vitamin in relation to the non-formulated fruit was higher in the FD (97-100\%) than in the SD samples (92-94\%). Although spray-drying process caused a significant $(\mathrm{p}<0.05)$ decrease in the content of ascorbic acid, the retention levels were high. Despite the high temperature used in the process, the drying occurs instantaneously, so that the sample does not stay in contact for a long time with the high temperature, which can guarantee the preservation of sensitive compounds (Agudelo et al., 2016). Moreover a slightly greater protective effect was observed when arabic gum and bamboo fiber were added together $\left(\mathrm{SD}_{1}\right)$, with $94 \%$ of retention for $92 \%$ in the sample containing only $A G\left(\mathrm{SD}_{2}\right)$. The degradation of vitamin $C$ by effect of the high temperature applied during spray-drying was also found by Langrish (2009) and Solval, Sundararajan, Alfaro, and Sathivel (2012), whereas the protective effects of AG addition were reported by Ali, Maqbool, Ramachandran, and Alderson (2010), among others.

As for $\alpha$-tocopherol, the levels were maintained in spray-dried samples (SD) compared to LG sample, whereas a significant loss $(p<0.05)$ was observed in GG in relation to the formulated freezedried samples (FD). This may be explained by the protection afforded by the shell materials added. Arabic gum (AG) is acknowledged to be an effective encapsulation agent due to its high water solubility, the low viscosity of its concentrated solutions relative to other hydrocolloid gums, and its ability to act as oil in water-emulsifier (Glicksman, 1983, pp. 7-30), which may explain the good retention of $\alpha$-tocopherol observed in the dried preparations. Bamboo fiber (BF) has not been used with this purpose in the literature, although the properties reported by the commercial company for the product (Vitacel ${ }^{\circledR}$ ), as a solute with synergistic effects with proteins, capillary effects (water and oil-binding) and binding characteristics independent of the temperature or the $\mathrm{pH}$ value, and no quality changes in extreme processing conditions, would also explain the efficiency in $\alpha$-tocopherol preservation. 
The phenolic chromatographic profile of Citrus paradisi var. Star Ruby (grapefruit) recorded at $280 \mathrm{~nm}$ is shown in Fig. 1. Compound characteristics, tentative identities and quantitative results are presented in Tables 3 and 4. Compounds were identified based on their chromatographic and UV and mass spectra characteristics. Up to eighteen compounds were detected, four of which were phenolic acid derivatives and fourteen flavonoids, mainly from the group of flavanones (Table 3 ). Most of these compounds have been previously reported by other authors in grapefruit or different Citrus species (Dugo et al., 2005; Peterson et al., 2006; Gattuso, Barreca, Gargiulli, Leuzzi, \& Caristi, 2007; Mullen, Marks, \& Crozier, 2007; Djoukeng, Arbona, Argamasilla, \& Gomez-Cadenas, 2008; Xu et al., 2008; Kelebek, 2010; Igual, García-Martínez, Camacho, \& Martínez-Navarrete, 2011; Zhang, Duan, Zang, Huang, \& Liu, 2011; Abad-García, Garmón-Lobato, Berrueta, Gallo, \& Vicente, 2012a, Abad-García et al., 2012b; Anagnostopoulou \& Kefalas, 2012; Goulas \& Manganaris, 2012; Moraga et al., 2012; Barreca et al., 2013; Sun et al., 2013; García-Castello, Rodriguez-Lopez, Mayor, Ballesteros, Conidi \& Cassano, 2015). Nonetheless, to the best of our knowledge, compounds 1,3 and 9 have not been previously described in grapefruit. Compound $1\left([\mathrm{M}-\mathrm{H}]^{-}\right.$at $\left.m / z 329\right)$ and 3 ([M$\mathrm{H}]^{-}$at $m / z$ 325) releasing $\mathrm{MS}^{2}$ fragments at $m / z 167$ (-162 u; [3,4dihydroxyphenylacetic acid-H] ${ }^{-}$) and $m / z 179$ (-146 u; [caffeic acid-H $]^{-}$), respectively, were tentatively assigned as 3,4dihydroxyphenylacetic acid hexoside and caffeic acid rhamnoside. Compound $9\left([\mathrm{M}-\mathrm{H}]^{-}\right.$at $m / z$ 563) presented a UV spectrum characteristic of a flavone and a fragmentation pattern that was coherent with an $O, C$-diglycoside of apigenin bearing pentosyl and hexosyl residues. The loss of $-120 \mathrm{u}$ leading to the ion at $\mathrm{m} / \mathrm{z} 443$ supported the presence of a $C$-attached hexose, while the absence of an ion $[(\mathrm{M}-\mathrm{H})-90]^{-}$pointed to a $6-\mathrm{C}$ attachment. The lack of an ion $[(\mathrm{M}-\mathrm{H})-132]^{-}$from the loss of the pentosyl residue suggested that this sugar was not linked to the aglycone but to the other sugar; this was confirmed by the presence of an abundant [(M-H)- $150]^{-}$ion at $m / z 413$, which according to Ferreres, Gil-Izquierdo, Andrade, Valentao, and Tomás-Barberán (2007) would be characteristic of an $\mathrm{O}$-attached pentose on the $\mathrm{C}$-glycosylating hexose. The O-glycosylation should not take place in the positions $6^{\prime \prime}, 4^{\prime \prime}$, or $3^{\prime \prime}$ of the hexose, otherwise the fragment $[(\mathrm{M}-\mathrm{H})-120]^{-}$would not be produced. The ion at $m / z 293$ would result from the fragment at $\mathrm{m} / \mathrm{z}$ 413 by further loss of a fragment of $120 \mathrm{u}$ (partial loss of the $C$ attached hexose). All in all, compound 9 was tentatively identified as apigenin $2^{\prime \prime}-O$-pentosyl-6- $C$-hexoside.

Flavanones were the dominant flavonoids in all grapefruit samples, representing about $93 \%$ of total flavonoids (Table 4). These results are similar to those compiled by Peterson et al. (2006). Various flavanone neohesperidosides (naringin, neohesperidin, poncirin) and rutinosides (narirutin, hesperidin, eriocitrin, and didymin) were identified in the analyzed grapefruit samples, with naringin and narirutin being the predominant phenolic compounds, as also reported by other authors (Gattuso et al., 2007; Moraga et al., 2012; Vanamala et al., 2006). Naringin is a characteristic component of grapefruit juices and the principal responsible for the bitter taste of this fruit (Mullen et al., 2007). Its mean concentration ranged between 560 and $680 \mathrm{mg} / 100 \mathrm{~g} d w$ in the two samples without carriers added (GG and GL), values similar to those reported by Moraga et al. (2012).

In general, the freeze-drying of formulated samples did not cause important changes in the phenolic composition, with percentages of retention of 90-95\% in the content of total phenolics in relation to the GG sample when expressed in relation to grapefruit own solutes (Table 4), whatever the type of shell material added. The lower relative retention observed in the sample $\mathrm{FD}_{1}$ might be a consequence of the rehydration it was submitted before freezedrying. Much greater losses of phenolic compounds were produced by the spray drying process, with mean percentages of retention around $58 \%$ in the content of total phenolics with respect to the starting material (LG). This might be explained by an

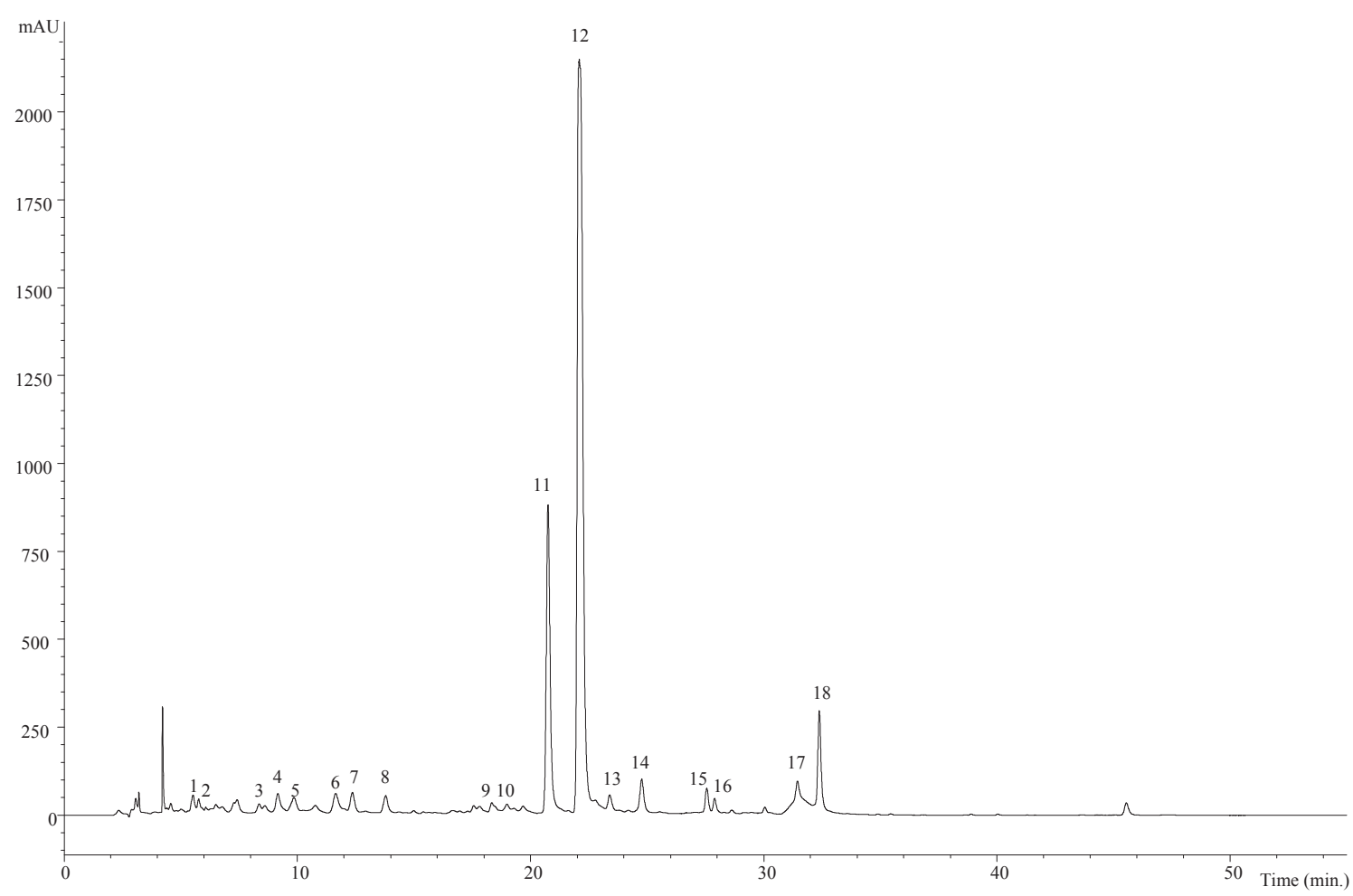

Fig. 1. HPLC profile of phenolic compounds in the freeze-dried liquidized grapefruit sample (LG), recorded at $280 \mathrm{~nm}$. 
Table 3

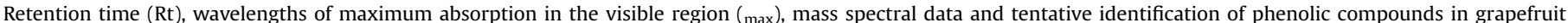
samples.

\begin{tabular}{|c|c|c|c|c|c|c|}
\hline Peak & $\begin{array}{l}\text { Rt } \\
(\min )\end{array}$ & $\begin{array}{l}\lambda \max \\
(\mathrm{nm})\end{array}$ & $\begin{array}{l}\text { Pseudomolecular ion [M- } \\
\mathrm{H}^{-}(m / z)\end{array}$ & $\operatorname{MS}^{2}(m / z)$ & Tentative identification & References $^{\mathrm{a}}$ \\
\hline 1 & 5.5 & 278 & 329 & $167(100)$ & $\begin{array}{l}\text { 3,4-Dihydroxyphenylacetic acid } \\
\text { hexoside }\end{array}$ & - \\
\hline 2 & 5.8 & 332 & 341 & 179(29),161(100),135(18) & Caffeic acid hexoside & 1,10 \\
\hline 3 & 8.3 & 328 & 325 & $179(100)$ & Caffeic acid rhamnoside & - \\
\hline 4 & 9.2 & 284,336 & 595 & $287(100)$ & Eriodictyol-7-O-rutinoside (eriocitrin) & $1,2,3,7,8,11$ \\
\hline 5 & 9.9 & 332 & 355 & $193(100)$ & Ferulic acid hexoside & 1,2 \\
\hline 6 & 11.6 & 336 & 593 & $505(14), 473(24), 383(18), 353(29), 325(11)$ & Apigenin 6,8 - $C$-diglucoside & $1,2,7,8,10$ \\
\hline 7 & 12.4 & 286,336 & 741 & $433(47), 271(100)$ & $\begin{array}{l}\text { Naringenin-7-O-rutinoside-4'-O- } \\
\text { glucoside }\end{array}$ & $1,2,6,10$ \\
\hline 8 & 13.8 & 286,334 & 741 & $433(14), 271(5)$ & $\begin{array}{l}\text { Naringenin-7-O-neohesperidoside-4'- } \\
O \text {-glucoside }\end{array}$ & $1,2,10$ \\
\hline 9 & 18.3 & 336 & 563 & $443(30), 413(100), 341(28), 313(15), 293(48)$ & Apigenin $2^{\prime \prime}$-O-pentosyl-6-C-hexoside & - \\
\hline 10 & 18.5 & 284,336 & 595 & $271(100)$ & Naringenin-O-dihexoside & 2,10 \\
\hline 11 & 20.7 & 282,336 & 579 & $271(100)$ & Naringenin-7-O-rutinoside (narirutin) & $1,3,4,5,7,8,9,10,11,12,13,14,15,16$ \\
\hline 12 & 22.1 & 284,336 & 579 & $459(22), 313(3), 295(3), 271(20)$ & $\begin{array}{l}\text { Naringenin-7-O-neohesperidoside } \\
\text { (naringin) }\end{array}$ & $1,3,4,5,7,8,9,10,11,12,13,14,15,16$ \\
\hline 13 & 23.4 & 284,338 & 609 & $301(100)$ & Hesperetin-7-O-rutinoside (hesperidin) & $1,3,4,5,8,9,10,12,14.15$ \\
\hline 14 & 24.8 & 284,338 & 609 & $301(100)$ & $\begin{array}{l}\text { Hesperetin-7-O-neohesperidoside } \\
\text { (neohesperidin) }\end{array}$ & $1,3,4,8,9,10,12,14,16$ \\
\hline 15 & 27.6 & 284,332 & 621 & $579(5), 501(14), 459(7), 271(12)$ & Acetyl naringin & 11 \\
\hline 16 & 27.9 & 284,336 & 723 & $661(13), 621(44), 579(100), 271(18)$ & $\begin{array}{l}\text { 3-Hydroxymethylglutaryl naringin } \\
\text { (Melitidin) }\end{array}$ & 11 \\
\hline 17 & 31.4 & 286,324 & 593 & $285(100)$ & $\begin{array}{l}\text { Isosakuranetin-7-O-rutinoside } \\
\text { (didymin) }\end{array}$ & $1,2,3,5,6,8,10,15,16$ \\
\hline 18 & 32.4 & 286,338 & 593 & $285(100)$ & $\begin{array}{l}\text { Isosakuranetin-7-O- neohesperidoside } \\
\text { (poncirin) }\end{array}$ & $1,2,3,5,7,8,10,15,16$ \\
\hline
\end{tabular}

a References: 1-Mullen et al. (2007); 2- Abad-García et al. (2012a); 3- Gattuso et al. (2007); 4- García-Castello et al. (2015); 5- Goulas and Manganaris (2012); 6- Barreca et al.

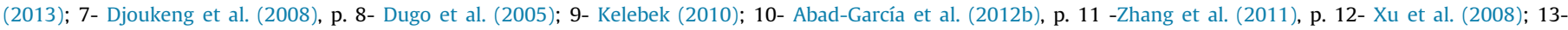
Anagnostopoulou \& Kefalas (2012); 14- Sun et al. (2013), p. 15-Igual et al. (2011), p. 16- Moraga et al. (2012).

Table 4

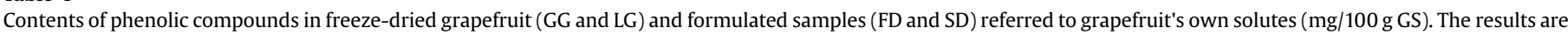
presented as mean \pm SD.

\begin{tabular}{|c|c|c|c|c|c|c|c|c|}
\hline Peak & GG & LG & $\mathrm{FD}_{1}$ & $\mathrm{FD}_{2}$ & $\mathrm{FD}_{3}$ & $\mathrm{FD}_{4}$ & $\mathrm{SD}_{1}$ & $\mathrm{SD}_{2}$ \\
\hline 1 & $6.9 \pm 0.5^{\mathrm{a}}$ & $1.71 \pm 0.02^{\mathrm{f}}$ & $2.35 \pm 0.03^{\mathrm{d}}$ & $1.19 \pm 0.03^{g}$ & $3.44 \pm 0.08^{c}$ & $2.31 \pm 0.01^{d}$ & $4.9 \pm 0.2^{b}$ & $1.01 \pm 0.04^{\mathrm{g}}$ \\
\hline 2 & $\operatorname{tr}$ & $\operatorname{tr}$ & $\operatorname{tr}$ & $\operatorname{tr}$ & $\operatorname{tr}$ & $\operatorname{tr}$ & $\operatorname{tr}$ & $\operatorname{tr}$ \\
\hline 3 & $\operatorname{tr}$ & $\operatorname{tr}$ & $\operatorname{tr}$ & $\operatorname{tr}$ & $\operatorname{tr}$ & $\operatorname{tr}$ & $\operatorname{tr}$ & $\operatorname{tr}$ \\
\hline 4 & $10.2 \pm 0.4^{\mathrm{a}}$ & $10.4 \pm 0.3^{a}$ & $8.46 \pm 0.09^{b}$ & $7.2 \pm 0.3^{c}$ & $8.4 \pm 0.2^{b}$ & $8.3 \pm 0.6^{b}$ & $5.8 \pm 0.3^{d}$ & $6.70 \pm 0.18^{c}$ \\
\hline 5 & $14.6 \pm 0.5^{\mathrm{a}}$ & $8.7 \pm 0.2^{b}$ & $7.89 \pm 0.18^{c}$ & $6.7 \pm 0.1^{\mathrm{e}}$ & $7.32 \pm 0.06^{\mathrm{d}}$ & $5.93 \pm 0.12^{f}$ & $6.8 \pm 0.3^{\mathrm{de}}$ & $5.58 \pm 0.03^{f}$ \\
\hline 6 & $38 \pm 2^{a}$ & $38.1 \pm 1.2^{\mathrm{a}}$ & $26.6 \pm 0.2^{\mathrm{b}}$ & $25.5 \pm 0.7^{\mathrm{b}}$ & $25.9 \pm 0.3^{\mathrm{b}}$ & $28 \pm 2^{\mathrm{b}}$ & $22.3 \pm 0.7^{c}$ & $25.6 \pm 1.6^{\mathrm{b}}$ \\
\hline 7 & $10.8 \pm 0.5^{\mathrm{a}}$ & $9.3 \pm 0.5^{b}$ & $9.98 \pm 0.13^{\mathrm{ab}}$ & $9.7 \pm 0.4^{b}$ & $9.53 \pm 0.03^{b}$ & $9.4 \pm 0.5^{b}$ & $6.1 \pm 0.2^{c}$ & $5.4 \pm 0.2^{c}$ \\
\hline 8 & $8.7 \pm 0.3^{a}$ & $7.9 \pm 0.3^{b}$ & $6.96 \pm 0.05^{c}$ & $7.8 \pm 0.2^{\mathrm{b}}$ & $7.9 \pm 0.3^{b}$ & $7.7 \pm 0.3^{b}$ & $4.92 \pm 0.07^{\mathrm{d}}$ & $4.41 \pm 0.09^{\mathrm{e}}$ \\
\hline 9 & $9.2 \pm 0.3^{\mathrm{a}}$ & $8.5 \pm 0.5^{\mathrm{a}}$ & $3.61 \pm 0.14^{c}$ & $5.55 \pm 0.05^{\mathrm{b}}$ & $6.1 \pm 0.7^{b}$ & $5.6 \pm 0.4^{b}$ & $2.58 \pm 0.05^{\mathrm{d}}$ & $2.91 \pm 0.12^{\mathrm{cd}}$ \\
\hline 10 & $\operatorname{tr}$ & $0.68 \pm 0.02$ & $\operatorname{tr}$ & $\operatorname{tr}$ & $\operatorname{tr}$ & $\operatorname{tr}$ & $\operatorname{tr}$ & $\operatorname{tr}$ \\
\hline 11 & $129.9 \pm 1.3^{b}$ & $142.4 \pm 0.3^{\mathrm{a}}$ & $113.38 \pm 0.06^{\mathrm{e}}$ & $118.9 \pm 1.2^{\mathrm{c}}$ & $117.2 \pm 0.8^{\mathrm{d}}$ & $120.18 \pm 0.09^{c}$ & $75.7 \pm 0.4^{\mathrm{f}}$ & $73.69 \pm 0.07^{g}$ \\
\hline 12 & $560 \pm 2^{\mathrm{b}}$ & $680.9 \pm 1.8^{\mathrm{a}}$ & $525 \pm 4^{\mathrm{e}}$ & $545 \pm 5^{c}$ & $532 \pm 4^{\mathrm{d}}$ & $548.7 \pm 1.1^{\mathrm{c}}$ & $331 \pm 3^{f}$ & $322.9 \pm 0.6^{g}$ \\
\hline 13 & $8.2 \pm 0.5^{\mathrm{a}}$ & $8.17 \pm 0.08^{a}$ & $6.52 \pm 0.02^{\mathrm{d}}$ & $7.4 \pm 0.3^{b c}$ & $6.92 \pm 0.06^{\mathrm{cd}}$ & $7.57 \pm 0.12^{\mathrm{ab}}$ & $5.5 \pm 0.3^{e}$ & $4.9 \pm 0.3^{\mathrm{f}}$ \\
\hline 14 & $10.2 \pm 0.3^{b}$ & $13.13 \pm 0.13^{\mathrm{a}}$ & $8.16 \pm 0.13^{c}$ & $8.7 \pm 0.2^{c}$ & $8.48 \pm 0.08^{c}$ & $8.8 \pm 0.6^{c}$ & $6.64 \pm 0.04^{\mathrm{d}}$ & $6.1 \pm 0.2^{\mathrm{e}}$ \\
\hline 15 & $8.4 \pm 0.3^{c}$ & $8.52 \pm 0.02^{c}$ & $8.24 \pm 0.08^{c}$ & $10.2 \pm 0.4^{\mathrm{a}}$ & $9.8 \pm 0.4^{\mathrm{ab}}$ & $9.6 \pm 0.2^{\mathrm{b}}$ & $5.2 \pm 0.2^{\mathrm{d}}$ & $4.14 \pm 0.03^{e}$ \\
\hline 16 & $3.67 \pm 0.09^{b}$ & $4.19 \pm 0.07^{\mathrm{a}}$ & $1.93 \pm 0.13^{\mathrm{e}}$ & $3.02 \pm 0.12^{c}$ & $2.59 \pm 0.08^{\mathrm{d}}$ & $2.38 \pm 0.15^{\mathrm{d}}$ & $2.11 \pm 0.12^{\mathrm{e}}$ & $0.79 \pm 0.07^{\mathrm{f}}$ \\
\hline 17 & $12.7 \pm 0.4^{\mathrm{d}}$ & $16.9 \pm 0.4^{\mathrm{b}}$ & $14.03 \pm 0.09^{c}$ & $18.6 \pm 0.5^{\mathrm{a}}$ & $17.22 \pm 0.12^{\mathrm{b}}$ & $16.7 \pm 0.2^{\mathrm{b}}$ & $6.9+ \pm 0.5^{\mathrm{e}}$ & $6.79 \pm 0.13^{e}$ \\
\hline 18 & $45.2 \pm 2.4^{\mathrm{a}}$ & $44.0 \pm 1.2^{\mathrm{ab}}$ & $49.5 \pm 0.6^{b}$ & $44 \pm 2^{\mathrm{ab}}$ & $43.3 \pm 1.4^{\mathrm{ab}}$ & $43.9 \pm 0.8^{\mathrm{ab}}$ & $27.9 \pm 1.6^{c}$ & $27.6 \pm 1.5^{c}$ \\
\hline Total phenolic acids & $14.7 \pm 0.3^{\mathrm{a}}$ & $10.4 \pm 0.2^{\mathrm{cd}}$ & $10.2 \pm 0.2^{d}$ & $7.87 \pm 0.09^{\mathrm{e}}$ & $10.76 \pm 0.02^{c}$ & $8.24 \pm 0.12^{\mathrm{e}}$ & $11.75 \pm 0.03^{b}$ & $6.59 \pm 0.02^{f}$ \\
\hline Total flavonoids & $856 \pm 6^{b}$ & $993.4 \pm 0.9^{\mathrm{a}}$ & $773 \pm 4^{\mathrm{e}}$ & $812 \pm 9^{c}$ & $796 \pm 8^{d}$ & $818 \pm 2^{c}$ & $502 \pm 6^{f}$ & $492 \pm 4^{f}$ \\
\hline Total phenolic compounds & $871 \pm 7^{b}$ & $1003.8 \pm 0.6^{\mathrm{a}}$ & $784 \pm 4^{\mathrm{e}}$ & $820 \pm 9^{c d}$ & $806 \pm 8^{\mathrm{d}}$ & $826 \pm 2^{c}$ & $514 \pm 6^{f}$ & $499 \pm 4^{\mathrm{g}}$ \\
\hline
\end{tabular}

tr: Traces. Different letters within the same row indicate significant differences $(p<0.05)$.

increased degradation favoured by the applied temperature.

\subsection{Effects on antioxidant activity}

In order to evaluate the effects of freeze-drying and spraydrying on the antioxidant activity, four chemical and biochemical in vitro assays were performed (Table 5). The antioxidant activity was expressed as $\mathrm{EC}_{50}$ values (mean $\pm \mathrm{SD}$ ). In general, $\mathrm{LG}$ and $\mathrm{GG}$ samples showed greater antioxidant capacity (lower $\mathrm{EC}_{50}$ values) than dried samples, being the LG extract the most active in all assays, consistent with its higher levels of vitamins and phenolic compounds. Relatively good retention of the antioxidant capacity was found in the formulated freeze-dried powders in relation to the non-formulated material, but in the case of the $\beta$-carotene bleaching assay, where a sharp decrease of the activity was observed in most of the processed samples. On the contrary, the 
Table 5

In vitro antioxidant activity presented as $\mathrm{EC}_{50}$ values $(\mathrm{mg} / \mathrm{mL})$ obtained for the different studied samples. The results are presented as mean $\pm \mathrm{SD}$.

\begin{tabular}{|c|c|c|c|c|}
\hline & \multirow[t]{2}{*}{ DPPH scavenging activity } & \multirow{2}{*}{$\frac{\text { Reducing Power }}{\text { Ferricyanide/Prussian blue assay }}$} & \multicolumn{2}{|l|}{ Lipid peroxidation inhibition } \\
\hline & & & $\beta$-Carotene bleaching inhibition & TBARS formation Inhibition \\
\hline \multicolumn{5}{|c|}{ Freeze dried grapefruit powder } \\
\hline GG & $7.11 \pm 0.13^{c}$ & $2.26 \pm 0.03^{\mathrm{d}}$ & $9.1 \pm 0.3^{\mathrm{e}}$ & $2.75 \pm 0.15^{\mathrm{d}}$ \\
\hline LG & $5.61 \pm 0.07^{\mathrm{f}}$ & $1.67 \pm 0.01^{\mathrm{e}}$ & $2.7 \pm 0.4^{\mathrm{f}}$ & $1.65 \pm 0.03^{g}$ \\
\hline $\mathrm{FD}_{1}$ & $7.21 \pm 0.11^{\mathrm{c}}$ & $3.1 \pm 0.3^{\mathrm{a}}$ & $16.1 \pm 0.4^{\mathrm{b}}$ & $1.86 \pm 0.06^{\mathrm{f}}$ \\
\hline $\mathrm{FD}_{2}$ & $6.1 \pm 0.2^{\mathrm{e}}$ & $2.44 \pm 0.04^{\mathrm{c}}$ & $9.5 \pm 0.4^{\mathrm{e}}$ & $2.04 \pm 0.03^{\mathrm{e}}$ \\
\hline $\mathrm{FD}_{3}$ & $6.4 \pm 0.3^{\mathrm{d}}$ & $2.72 \pm 0.02^{\mathrm{b}}$ & $14.1 \pm 0.5^{\mathrm{d}}$ & $3.0 \pm 0.3^{c}$ \\
\hline $\mathrm{FD}_{4}$ & $6.3 \pm 0.5^{\mathrm{de}}$ & $2.51 \pm 0.07^{c}$ & $14.6 \pm 0.3^{c}$ & $4.0 \pm 0.2^{b}$ \\
\hline \multicolumn{5}{|c|}{ Spray dried grapefruit powder } \\
\hline $\mathrm{SD}_{1}$ & $8.61 \pm 0.10^{\mathrm{a}}$ & $2.73 \pm 0.01^{\mathrm{b}}$ & $19.2 \pm 0.7^{\mathrm{a}}$ & $2.13 \pm 0.04^{\mathrm{e}}$ \\
\hline $\mathrm{SD}_{2}$ & $7.6 \pm 0.3^{\mathrm{b}}$ & $2.50 \pm 0.07^{c}$ & $19.0 \pm 0.7^{\mathrm{a}}$ & $4.17 \pm 0.06^{\mathrm{a}}$ \\
\hline
\end{tabular}

Different letters within the same column indicate significant differences $(p<0.05)$.

spray-dried samples showed the lowest antioxidant activity, which is coherent with a greater loss was produced in their levels of phenolic compounds. Pearson's statistical correlation analysis was used to establish correlations between the antioxidant capacity and the studied bioactive compounds. The obtained results showed that the most significant contribution to DPPH scavenging activity $(-0.82, p<0.05)$ and inhibition of $\beta$-carotene blanching $(-0.76$, $p<0.05$ ), and was provided by total phenolic compounds specifically by flavonoids. However, these compounds did not present significant correlations with the reducing power $(-0.43, p>0.05)$ and TBARS formation inhibition $(-0.32, p>0.05)$.

The antioxidant activity of flavonoids as electron or hydrogen donors relates to the reduction potentials and reactivity of the substituent reactive groups, so in DPPH scavenging activity the compounds, didymin $(-0.91, p<0.05)$, naringin $(-0.8405$, $p<0.05)$, narirutin $(-0.81, p<0.05)$, poncirin $(0.81, p<0.05)$ and hesperidin $(-0.73, p<0.05)$ presented the best correlations, while in the inhibition of $\beta$-carotene bleaching, melitidin $(-0.94$, $p<0.05)$, nehosperidin $(-0.90, p<0.05)$, and apigenin $2^{\prime \prime}-O$-pentosyl-6-C-hexoside $(-0.84, p<0.05)$ were the most promising compounds.

There are many studies in the literature that also described a high correlation between phenolic compounds content and antioxidant capacity of many fruits (Deepa, Kaura, George, Singh, \& Kapoor, 2007; Contreras-Calderón, Calderón-Jaimes, GuerraHernández, \& García-Villanova, 2011), attributing this behaviour to the redox properties of these compounds, which allow them to act as reducing agents, hydrogen donors and singlet oxygen quenchers (Miranda et al., 2010). In extracts from Rio Red grapefruit, Jayaprakasha, Girennavar, and Patil (2008) also reported a high correlation $\left(R^{2}>0.94\right)$ between total polyphenol content and radical scavenging activity by the DPPH method.

Ascorbic acid $(-0.7890, p<0.05)$ and $\alpha$-tocopherol $(-0.54$, $p<0.05)$ contributed to increase the reducing power, in addition to some individual phenolic compounds suggesting that all these compounds can work synergistically in the protection against oxidative damages.

\section{Conclusions}

The results obtained in the present study showed that adding arabic gum and bamboo fiber to obtain grapefruit powder by freeze-drying is a good alternative, maintaining the functional components of the fruit, namely antioxidant vitamins and phenolic compounds, and antioxidant properties. However, in the case of spray-drying it lead to a loss of bioactive compounds affecting the functional quality of the fruit. In both cases, the addition of arabic gum helps protect especially the $\alpha$-tocopherol against degradation by acting as encapsulation agents. Bamboo fiber added together with the gum showed a protective effect against ascorbic acid and total phenols degradation. Clearly the largest contribution to the antioxidant capacity of the studied samples is provided by the presence of phenolic compounds, mainly flavonoids that can effectively scavenge various reactive oxygen species or free radicals under in vitro conditions.

\section{Acknowledgment}

The authors thank the Ministerio de Economía y Competitividad for the financial support given throughout the Project AGL 201239103, and to the Foundation for Science and Technology and FEDER under Program PT2020 for financial support to CIMO (UID/ AGR/00690/2013), and L. Barros (SFRH/BPD/107855/2015) grant. To POCI-01-0145-FEDER-006984 (LA LSRE-LCM), funded by ERDF, through POCI-COMPETE2020 and FCT.

\section{References}

Abad-García, B., Berrueta, L. A., Garmón-Lobato, S., Urkaregi, A., Gallo, B. \& Vicente, F. (2012b). Chemometric characterization of fruit juices from Spanish cultivars according to their phenolic compound contents: I. citrus fruits. Journal of Agricultural and Food Chemistry, 60, 3635-3644.

Abad-García, B. Garmón-Lobato, S., Berrueta, L. A., Gallo, B., \& Vicente, F. (2012a). On line characterization of 58 phenolic compounds in citrus fruit juices from Spanish cultivars by high-performance liquid chromatography with photodiode-array detection coupled to electrospray ionization triple quadrupole mass spectrometry. Talanta, 99, 213-224.

Agudelo, C., Igual, M., Camacho, M., \& Martínez-Navarrete, N. (2016). Effect of process technology on the nutritional, functional, and physical quality of grapefruit powder. Food Science and Technology International, 23(1), 61-74.

Ali, A., Maqbool, M., Ramachandran, S., \& Alderson, P. G. (2010). Gum arabic as a novel edible coating for enhancing shelf-life and improving postharvest quality of tomato (Solanum lycopersicum L.) fruit. Postharvest Biology and Technology, 58, $42-47$.

Anagnostopoulou, M. A., \& Kefalas, P. (2012). Bioflavonoid profile of citrus juices from Greece. Biomedical Chromatography, 26, 1252-1268.

Barreca, D., Bisignano, C., Ginestra, G., Bisignano, G., Bellocco, E., Leuzzi, U., et al. (2013). Polymethoxylated, C- and O-glycosyl flavonoids in tangelo (Citrus reticulata $\mathrm{x}$ Citrus paradisi) juice and their influence on antioxidant properties. Food Chemistry, 141, 1481-1488.

Barros, L., Heleno, S. A., Carvalho, A. M., \& Ferreira, I. C. F. R. (2010). Lamiaceae often used in Portuguese folk medicine as a source of powerful antioxidants: Vitamins and phenolics. LWT - Food Science and Technology, 43, 544-550.

Chun, J., Lee, J., Ye, L., Exler, J., \& Eitenmiller, R. R. (2006). Tocopherol and tocotrienol contents of raw and processed fruits and vegetables in the United States diet. Journal of Food Composition and Analysis, 19, 196-204.

Contreras-Calderón, J., Calderón-Jaimes, L., Guerra-Hernández, E., \& GarcíaVillanova, B. (2011). Antioxidant capacity, phenolic content and vitamin C in pulp, peel and seed from 24 exotic fruits from Colombia. Food Research International, 44, 2047-2053.

Deepa, N., Kaura, C., George, B., Singh, B., \& Kapoor, H. (2007). Antioxidant constituents in some sweet pepper (Capsicum annuum L.) genotypes during maturity. LWT: Food Science and Technology, 40, 121-129.

Díaz-Juárez, J. A., Tenorio-López, F. A., Zarco-Olvera, G., del Valle-Mondragón, L. Torres-Narváez, J. C., \& Pastelín-Hernández, G. (2009). Effect of Citrus paradisi extract and juice on arterial pressure both in vitro and in vivo. Phytoterapy Research, 23, 948-954. 
Djoukeng, J. D., Arbona, V., Argamasilla, R., \& Gomez-Cadenas, A. (2008). Flavonoid profiling in leaves of citrus genotypes under different environmental situations. Journal of Agricultural and Food Chemistry, 56, 11087-11097.

Dow, C. A., Going, S. B., Chow, H. H. S., Patil, B. S., \& Thomson, C. A. (2012). The effects of daily consumption of grapefruit on body weight, lipids, and blood pressure in healthy, overweight adults. Metabolism: Clinical and Experimental, 61, 1026-1035.

Dugo, P., Presti, M. L., Öhman, M., Fazio, A., Dugo, G., \& Mondello, L. (2005). Determination of flavonoids in citrus juices by micro-HPLC-ESI/MS. Journal of Separation Science, 28, 11491156.

Fang, Z., \& Bhandari, B. (2012). Comparing the efficiency of protein and maltodextrin on spray drying of bayberry juice. Food Research International, 48, 478-483.

Fernandes, Â., Barreira, J. C. M., Antonio, A. L., Oliveira, M. B. P. P., Martins, A., \& Ferreira, I. C. F. R. (2016). Extended use of gamma irradiation in wild mushrooms conservation: Validation of $2 \mathrm{kGy}$ dose to preserve their chemical characteristics. LWT - Food Science and Technology, 67, 99-105.

Fernandes, F. A. N., Rodrigues, S., Law, C. L., \& Mujumdar, A. S. (2011). Drying of exotic tropical fruits: A comprehensive review. Food and Bioprocess Technology, 4, 163-185.

Ferreres, F., Gil-Izquierdo, A., Andrade, P. B., Valentao, P., \& Tomás-Barberán, F. A (2007). Characterization of C-glycosyl flavones O-glycosylated by liquid chromatography-tandem mass spectrometry. Journal of Chromatography A, 1161, 214-223.

García-Castello, E. M., Rodríguez-López, A. D., Mayor, L., Ballesteros, R., Conidi, C., \& Cassano, A. (2015). Optimization of conventional and ultrasound assisted extraction of flavonoids from grapefruit (Citrus paradisi L.) solid wastes. LWT Food Science and Technology, 64, 1114-1122.

Gattuso, G., Barreca, D., Gargiulli, C., Leuzzi, U., \& Caristi, C. (2007). Flavonoid composition of citrus juices. Molecules, 12, 1641-1673.

Glicksman, M. (1983). In M. Glicksman (Ed.), Gum arabic. In food hydrocolloids. Boca Raton, FL: CRC Press.

Gorinstein, S., Leontowicz, H., Leontowicz, M., Krzeminski, R., Gralak, M., DelgadoLicon, E., et al. (2005). Changes in plasma lipid and antioxidant activity in rats as a result of naringin and red grapefruit supplementation. Journal of agricultural and food chemistry, 53, 3223-3228.

Goulas, V., \& Manganaris, G. A. (2012). Exploring the phytochemical content and the antioxidant potential of citrus fruits grown in Cyprus. Food Chemistry, 131, 39-47.

Igual, M., García-Martínez, E., Camacho, M. M., \& Martínez-Navarrete, N. (2011). Changes in flavonoid content of grapefruit juice caused by thermal treatment and storage. Innovative Food Science and Emerging Technologies, 12, 153-162.

Jayaprakasha, G. K., Girennavar, B., \& Patil, B. S. (2008). Radical scavenging activities of Rio Red grapefruits and Sour orange fruit extracts in different in vitro model systems. Bioresource Technology, 99, 4484-4494.

Kelebek, H. (2010). Sugars, organic acids, phenolic compositions and antioxidant activity of grapefruit (Citrus paradisi) cultivars grown in Turkey. Industrial Crops and Products, 32, 269-274.

Langrish, T. A. G. (2009). Degradation of vitamin C in spray dryers and temperature and moisture content profiles in these driers. Food and Bioprocess Technology, 2, 400-408.

Mertens-Talcott, S. U., Zadezensky, I., De Castro, W. V., Derendorf, H., \& Butterweck, V. (2006). Grapefruit-drug interactions: Can interactions with drugs be avoided? Journal of clinical pharmacology, 46, 1390-1416.

Miranda, M., Vega-Gálvez, A., López, J., Parada, G., Sanders, M., Aranda, M., et al.
(2010). Impact of air-drying temperature on nutritional properties, tota phenolic content and antioxidant capacity of quinoa seeds (Chenopodium quinoa Willd.). Industrial Crops \& Products, 32, 258-263.

Moraga, G., Igual, M., García-Martínez, E., Mosquera, L. H., \& Martínez-Navarrete, N. (2012). Effect of relative humidity and storage time on the bioactive compounds and functional properties of grapefruit poder. Journal of Food Engineering, 112, 191-199.

Mullen, W., Marks, S. C., \& Crozier, A. (2007). Evaluation of phenolic compounds in commercial fruit juices and fruit drinks. Journal of Agricultural and Food Chemistry, 55, 3148-3157.

Park, H. J., Lee, Y., \& Eun, J. B. (2016). Physicochemical characteristics of kimchi powder manufactured by hot air drying and freeze drying. Biocatalysis and Agricultural Biotechnology, 5, 193-198.

Pereira, C., Barros, L., Carvalho, A. M., \& Ferreira, I. C. F. R. (2013). Use of UFLC-PDA for the analysis of organic acids in thirty-five species of food and medicinal plants. Food Analytical Methods, 6, 1337-1344.

Peterson, J. J., Beecher, G. R., Bhagwat, S. A., Dwyer, J. T., Gebhardt, S. E. Haytowitz, D. B., et al. (2006). Flavanones in grapefruit, lemons, and limes: A compilation and review of the data from the analytical literature. Journal of Food Composition and Analysis, 19, 74-80.

Pinela, J., Barros, L., Dueñas, M., Carvalho, A. M., Santos-Buelga, C., \& Ferreira, I. C. F. R. (2012). Antioxidant activity, ascorbic acid, phenolic compounds and sugars of wild and commercial Tuberaria lignosa samples: Effects of drying and oral preparation methods. Food Chemestry, 135, 1028-1035.

Solval, K. M., Sundararajan, S., Alfaro, L., \& Sathivel, S. (2012). Development of cantaloupe (Cucumis melo) juice powders using spray drying technology. LWT Food Science and Technology, 46, 287-293.

Sun, Y., Qiao, L., Shen, Y., Jiang, P., Chen, J., \& Ye, X. (2013). Phytochemical profile and antioxidant activity of physiological drop of citrus fruits. Journal of Food Science $78,37-42$.

Tonon, R. V., Brabet, C., Pallet, D., Brat, P., \& Hubinger, M. D. (2009). Physicochemical and morphological characterisation of açai (Euterpe oleraceae Mart.) powder produced with different carrier agents. International Journal of Food Science and Technology, 44, 1950-1958.

USDA United States Department of Agriculture, \& Agricultural Research Service. (2011). USDA national nutrient database for standard reference, release 28. Full report (all nutrients) 09112, grapefruit, raw, pink and red, all areas. Available from: http://www.ars.usda.gov/services/docs.htm?docid=8964 Accessed 15.02.16.

Vanamala, J., Cobb, J., Turner, N. D., Lupton, J. R., Yoo, K. S., Pike, L. M., et al. (2005) Bioactive compounds of grapefruit (Citrus paradisi Cv. Rio Red) respond differently to postharvest irradiation, storage, and freeze drying. Journal of Agricultural and Food Chemistry, 53, 3980-3985.

Vanamala, J., Reddivari, L., Yoo, K. S., Pike, L. M., \& Patil, B. S. (2006). Variation in the content of bioactive flavonoids in different brands of orange and grapefruit juices. Journal of Food Composition and Analysis, 19, 157-166.

Xu, G., Liu, D., Chen, J., Ye, X., Ma, Y., \& Shi, J. (2008). Juice components and capacity of citrus varieties cultivated in China. Food Chemistry, 106, 545-551.

Zhang, M., Duan, C., Zang, Y., Huang, Z., \& Liu, G. (2011). The flavonoid composition of flavedo and juice from the pummelo cultivar (Citrus grandis (L.) Osbeck) and the grapefruit cultivar (Citrus paradisi) from China. Food Chemestry, 129 $1530-1536$.

Zou, Z., Xi, W., Hu, Y., Nie, C., \& Zhou, Z. (2015). Antioxidant activity of citrus fruits. Food Chemistry, 196, 885-896. 